\section{Cover illustration: Be on the lookout ...}

One of the stalk eyed flies, Achias longividens (Walker), illustrated on the cover is found in South East Asia (this specimen is from Borneo) and shows a curious ocular adaptation with astonishing visual mechanisms and visual fields. The most instructive element of the biology of this animal, however, may be the understanding of its genetics. Its compound eyes are located at both ends of long stalks. These flies exhibit ocular sexual dimorphism which is not all that unusual in the dipterans as the males of many species have better acuity or different types of eyes from those of the females. Male ornaments that influence sexual selection are also not rare in the insect world, or even in the dipterans. But ornamented eyes are unusual. In at least eight acalyperate families, protuberences that are stretched out to form stalks can be found on the males and usually on the females of the same species. In most instances, the males have the longer "stalks" and sometimes spectacularly so. Investigators have described at least some male Crytodopsis whitei flies (another Borneo species) as having an 8 $\mathrm{mm}$ body length with eye stalks that have a combined span of $20 \mathrm{~mm}$ (Burkhardt D, et al, f Comp Physiol A 1994;1774:61-4). One wonders how such a creature would be airworthy.

These stalks are used by the males to help claim and retain territory. The males may engage in ritualised or even real fights in which there is simply a threat display or actual "jousting" with these stalks. Competitors are driven away by the more dominant male-usually the one with the longer stalks.

The evolution of such ornamental stalks

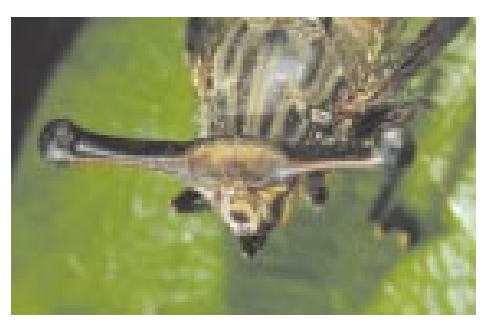

complete. Females don't always get the Y-mds gene male, and the $\mathrm{X}$ suppressor gene provides more females in a brood than the Y-mds gene provides males in a brood. The Y-mds gene does nothing to the normal $\mathrm{X}$ chromosome, and the Y-mds gene is probably "expensive," and it would appear that the Y-mds gene confers a disadvantage when paired with a normal X. Hence, at equilibrium, there is a preponderance of females, and the female selects for the Y-mds gene and longer stalks.

The visual mechanisms are no less interesting. Body length, stalk length, and the number of ommatidia are directly and closely related for any male of any individual species with enlarged stalks. The ommatidia number approximately 2600 per eye in a large male. The visual field is probably the most complete in the animal kingdom. Without moving its head, this fly can see all of the entire visual space around it with the exception of but a few millimetres directly surrounding its body. They have an extensive binocular visual field in the median plane and "stereopsis" (or at least binocular field overlap) of no less than $25^{\circ}$ (directly overhead vertically) extending to as large as $135^{\circ}$ in the frontal-ventral quadrant. This incredible species has a binocular field throughout the median plane and perhaps as many as $70 \%$ of the ommatidia of each eye have binocular partners in the opposite compound eye. There is an area of the visual field where objects are viewed with more detail which, for lack of a better word, we will call the fovea, although it is not a true fovea. This region is must be unusual, and what is already known is extraordinarily so. Having been found in amber in the region of the Baltic and dated approximately to the early Tertiary period, we know these creatures are not late comers to the biological table, although the eye stalks of these preserved specimens were shorter than those of current description. As you might imagine, to get from a shorter to a longer stalk evolutionarily, the females must preferentially select for longer stalks, and they do, although this is not an entirely exclusionary process. Interestingly enough, the imagines (adult flies) of these flies are approximately two thirds female. Some broods are nearly $100 \%$ female. These two facts, a preponderance of females in the broods and female selection for longer stalks, have been investigated and led to startling conclusions requiring counterintuitive logic. Recently, Wilkinson and others have shown that this female preference for longer eyestalks is seen because the eyestalks are really a proxy for genetic quality and a surprising influence on the reproductive value of the offspring (Wilkinson, et al, Male eye span in stalk-eyed flies indicates genetic quality by meiotic drive suppression. Nature 1998;391:276-9). These investigators believe, with good evidence to support their conclusions, that some or all of the longer eye stalk gene(s) are on the Y chromosome and are linked to a meiotic drive suppression gene. (No, I didn't know what that was either.) Sex preference of progeny, it turns out, can be manipulated by the $\mathrm{X}$ and $\mathrm{Y}$ chromosome during spermatogenesis. An " $\mathrm{X}$ linked meiotic driving chromosome" that has the capability of destroying many, if not all, Y chromosome bearing sperm, is thought to have evolved leading to many more females than males in a brood. This would cause extinction of the species without a similar counter evolution of a "Y meiotic drive suppression" gene (Y-mds). The Y-mds gene is probably linked to the gene for stalk length, and is preferred by females, even if unconsciously. This occurs because females that mate with those males who have the Y-mds gene will have broods of predominantly males. Since males are outnumbered 2 to 1 , if a female has more males in her brood, and each individual male will sire more offspring than each individual female (because of the 2:1 ratio), the female that mates with the male with the Y-mds gene will pass more of her genes on to successive generations. Why, then, don't the populations equalise or become male? Good question, and the answer is difficult, complex, and probably not found in the frontal and horizontal plane and corresponds to an area on each compound eye where the angle between the ommatidial faces is approximately $1^{\circ}$. These foveae from the two compound eyes have binocular overlap (Burkhardt D, et al, f Comp Physiol A 1994;1774:61-4). eyes, and the dipteran flies offer one more variation that should be mentioned. Most of the dipterans have neural superposition compound eyes. Each individual ommatidium of superposition compound eyes has photoreceptive elements, called rhabdomeres, that comprise the rhadom just as other insects do. In these flies, though, the rhabdomeres are not fused together as they are, for example, in butterflies. The seven individual rhabdomeres are separated at the base of the cone of each ommatidium. Each rhabdomere, then, has a separate image or portion thereof compared with its neighbour within the ommatidia. Neurologically, this becomes distinctly different from other ommatidial visual mechanisms from this point on. As the individual rhabdomere sends its signal distally and exits the ommatidium, that signal is matched domeres in seven other ommatidia. This is astonishingly complex, and perhaps could be considered analogous to a telephone cable leading from a large office building to a switching station, although this analogy does not do justice to this neural superposition system. This complex neuronal system allows for a dramatic increase in the photon sensitivity of the eyes (sevenfold to be exact) without enlarging the rhabdom size and sacrificing acuity. This allows the insect that possesses this system to be more of a crepuscular animal - that is, to be more active into twilight than other animals with different forms of compound eyes. Land and Fernald calculate that this would add as much as 30 minutes to their effective day (Land MF, Fernald RD, The evolution of eyes. Annu Rev Neurosci 1992;15:1-29).

These dipterans are pushing the envelope of vision and genetics with a single stalk. Be on the lookout for them.-Ivan R Schwab, MD, UC Davis Department of Ophthalmology, 860 Y Street, Ste 2400, Sacramento, CA 95817,USA (rschwab@ucdavis.edu)

Thanks to Lynn Kimsey, $\mathrm{PhD}$, and the Bohart Museum of Entomology at the University of California, Davis for the specimen of Achias longividens (Walker).
Previous cover essays have described other forms of compound with seven other individual signals from seven adjacent rhab- 